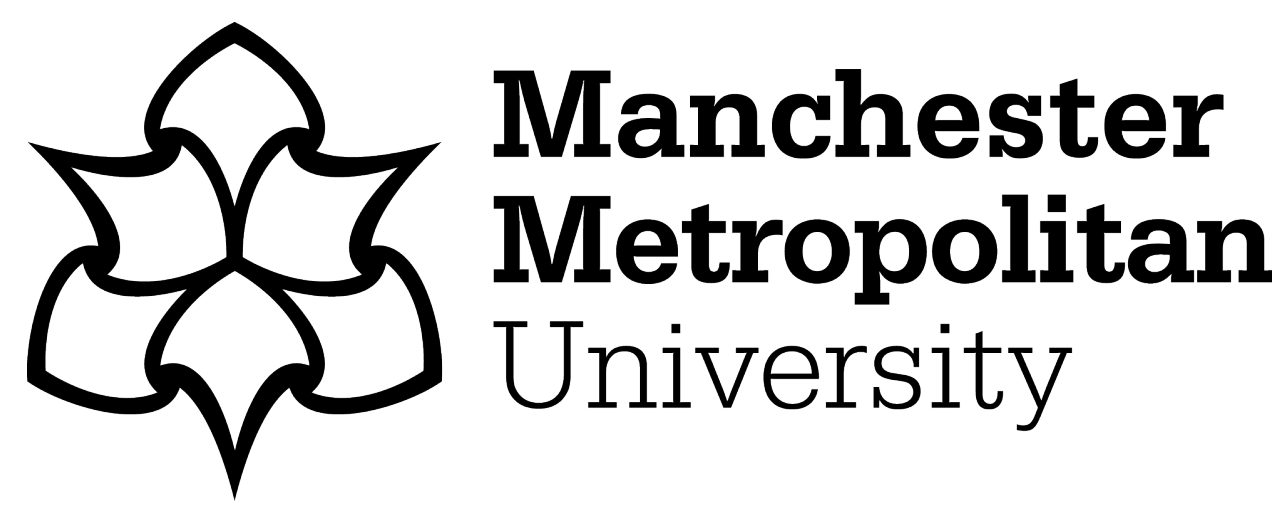

Luckson, Manju ORCID logoORCID: https://orcid.org/0000-0002-3547-3292, Duncan, Fiona, Rajai, Azita and Haigh, Carol ORCID logoORCID: https://orcid.org/0000-0002-5399-6003 (2018) Exploring the research culture of nurses and Allied Health Professionals (AHPs) in a research focused and a non-research-focused healthcare organisation in the UK. Journal of Clinical Nursing, 27 (7-8). ISSN 0962-1067

Downloaded from: https://e-space.mmu.ac.uk/623136/

Version: Accepted Version

Publisher: Wiley

DOI: https://doi.org/10.1111/jocn.14264

Please cite the published version 


\title{
Exploring the research culture of nurses and allied health professionals (AHPs) in a research-focused and a non- research-focused healthcare organisation in the UK
}

\author{
Manju Luckson PhD, RN, MSc, Assistant Research Delivery Manager, Senior Lecturer \\ Manchester $^{1,2}$ (D) | Fiona Duncan PhD, RN, MSc, Research Fellow ${ }^{2}$ | Azita Rajai MSc, \\ Medical Statistician $^{1,3}$ | Carol Haigh PhD, RN, MSc, Professor in Nursing ${ }^{4}$
}

${ }^{1}$ NIHR Manchester Biomedical Research Centre, Manchester University NHS Foundation Trust, Manchester Academic Health Science Centre, Manchester, UK

${ }^{2}$ Faculty of Health, Psychology and Social care, Manchester Metropolitan University, Manchester, UK

${ }^{3}$ Institute of Population Health, Faculty of Medical and Human Sciences, University of Manchester, Manchester, UK

${ }^{4}$ Nursing Department, Health, Rehabilitation and Psychology, Manchester Metropolitan University, Manchester, UK

\section{Correspondence}

Manju Luckson, Research and Innovation Division NIHR Manchester Biomedical Research Centre, Manchester University NHS Foundation Trust, Manchester Academic Health Science Centre, 29 , Grafton Street, M13 9WU, Manchester, UK Emails: Manju.luckson@cmft.nhs.uk; mcpallam@yahoo.com

Funding information Manchester Metropolitan University, Grant/ Award Number: PhD Studentship
Aims and objectives: To explore the research culture of nurses and allied health professionals (AHPs) in the UK and the influence of a dedicated research strategy and funding. It is important to understand the culture in order to effectively promote evidence-based patient care. The primary aim of this research was to explore the influence of research-focused exposure on the research culture of nurses and AHPs in the UK and to identify whether there was a difference in the research culture between a research-focused and non-research-focused clinical area (City and Riverside Hospitals).

Background: This is a unique and novel study that explored and compared the research culture stance of both AHPs and nurses.

Design: Methods: A mixed methods design was used in this study. Tools used included the "Research Capacity and Culture tool" as an online survey, three focus group discussions and five semi-structured interviews with senior managers. Focus groups included research-naive groups from both hospitals and a research-active group from City Hospital.

Results: There were 224 responses received from 941 surveys with a 24\% response rate. Descriptive statistics of the survey results indicated that there was a difference $(p=.001)$ in the mean score of the research culture between City Hospital (5.35) and Riverside Hospital (3.90), but not between nurses and AHPs ( $p=.12$ ). Qualitative data findings from the framework analysis were congruent and supported the survey results. The results provided empirical evidence to support a whole-level approach in order to improve the research culture. Both findings showed that there may not be any difference in the research culture between professional groups. Importantly, new evidence is presented to suggest that there were crucial communication issues which were hampering the research culture and there was a lack of support at the middle management level which needed to be tackled to improve the research culture of nurses and AHPs.

Relevance to clinical practice: The study highlighted the need to include a wholelevel approach in organisation to improve research culture and to include 


\section{1 | INTRODUCTION}

The National Health Service (NHS) in the United Kingdom (UK) has always been under pressure to improve patient care, despite limited resources. This was highlighted by the Francis Report (Francis, 2010, 2013) which focused on how the set-up of the entire health and social care system in England could aid or hinder nurses and other staff to deliver quality patient care. It illustrated the culture of the NHS and the impact it has on the ability of staff to raise concerns. Following the Francis Report (Francis, 2010, 2013), the Nursing and Midwifery Council (NMC) produced a response clearly indicating that, first and foremost, the responsibilities of all nurses are to care for and to safeguard the public. The NMC (2013) stated that, through autonomous practice, nurses should be responsible and accountable for providing a safe, compassionate and person-centred, evidence-based nursing care that respects and maintains a patient's dignity and human rights (Nursing and Midwifery Council, 2013). In 2014, Health Education England (HEE), in partnership with the Nursing and Midwifery Council, published a Research and Innovation Strategy for all healthcare staff: "The shape of Caring Review" aimed to build on its recommendations (Willis, 2015). These initiatives had moved research activity and productivity up the healthcare agenda to improve patient outcomes.

The medical profession historically has been considered to be a much more research-focused profession with a research culture and mindset, when compared to nursing and allied health professionals. Approximately $6 \%$ of the medical workforce in the UK are clinical academics who are involved in direct patient care whilst also undertaking research and teaching future generations of doctors. Around half of these individuals hold clinical professorial posts, which represent $3.4 \%$ of the medical workforce as a whole, with the remainder in training grades, developing their clinical expertise alongside their research and academic skills (Fitzpatrick, 2013). The research culture and research capacity of nurses and AHPs have been underresearched and have been recognised as an international issue by several countries including Australia, the United States of America and the UK (Albert \& Mickan, 2003; Department of Health, 2000; Frontera et al., 2005; Segrott, Mclvor, \& Green, 2006). Also, nurses and AHPs were the professionals most often reported in the literature as being in the greatest need of increased research capacity, due to their weaker research skill and activity base (Albert \& Mickan, 2003; Mant, 1997). Moreover, there remained little empirical evidence about how effective the research culture was of nonmedical

\section{What does this paper contribute to the wider global clinical community?}

- The findings showed that there may not be any difference in the research culture between professional groups.

- Importantly, new evidence is presented to suggest that there were crucial communication issues which were hampering the research culture and there was a lack of support at the middle management level which needed to be tackled to improve the research culture of nurses and AHPs.

- The study highlighted the need to include a whole-level approach in organisation to improve research culture and to include communication within the Cooke's framework if evidence-based practice is to influence the quality of patient care.

staff such as nurses and AHPs. This is of national and international importance for both professions. Hence, this study explored the research culture of nurses and AHPs based in two hospitals in the Northwest of England.

\subsection{Definition of terms}

The term research culture is defined by Cheetham (2007: 5) as follows:

The research culture is the structure that gives [research behaviour] significance and that allows us to understand and evaluate the research activity.

A research culture is essential to research capacity building, and research capacity building fosters research culture (Wilkes \& Jackson, 2013). The $\mathrm{DOH}$ has adopted the definition of research capacity building (RCB) promulgated by Trostle (1992:1321) (and as used in this study):

A process of individual and institutional development which leads to higher levels of skills and greater ability to perform useful research. 


\section{I LITERATURE REVIEW}

Since 1995, there have been policy initiatives in the UK to build research capacity amongst nurses and AHPs through a national-coordinated approach. However, the extent to which nurses and AHPs were actually skilled, interested, involved or had undertaken research activities remained unclear. Similarly, there has been large volume of the literature about evidence-based practice, but an absence of the literature on nurses and AHPs undertaking research (Woodward, Webb, \& Prowse, 2007). Review has identified the problems in developing research capacity including barriers and has looked at the evaluations for RCB activities (Conrad, 2008; Happell, 2008; Jenerette et al., 2008; Moore, Crozier, \& Kite 2012).

The existing literature in this field had mainly concentrated on the challenges of developing research capacity, rather than research culture, and had explored some evaluations for RCB (Conrad, 2008; Happell, 2008; Jenerette et al., 2008; Moore et al. 2012). Also, these studies on RCB were carried out at various places internationally and within different clinical settings and different health professions (Moore 1997, Segrott et al., 2006). There are other studies which have looked at research barriers in academic settings (Daniels, 2002; Orme \& Powell, 2008; Shera, 2008), in different individual professional groups (Moore 1997, Rosser, Godwin, \& Seguin,2010; Waine, Magill-Evans, \& Pain,1997) or in a specific area of health (Hassanein, 1988; Cooke, Owen, \& Wilson, 2002; Frontera et al., 2005). However, there have been no studies on research culture or capacity building which combine and compare multidisciplinary groups of nurses and AHPs together and which compare between two healthcare settings as this research study has carried out.

In the literature, there are other frameworks looking at different aspects of research culture, capacity and research use. The Estabrooks (1999) conceptual framework looked at the theoretical understanding of research use. The Promoting Action on Research Implementation in Health Services (PARIHS) framework (Kitson, Harvey, \& McCormack, 1998) was developed to look at the implementation of evidence-based practice in the UK. However, the context assessment index by McCormack, McCarthy, Wright, Slater, and Coffey (2009) was developed because there was no established method for assessing "context" if using the PARIHS framework. In 2005, Cooke's framework was developed to measure the impact of RCB at four levels, based on six principles of RCB which were to:

- develop skills and confidence,

- support linkages and partnerships,

- ensure that the research is "close to practice,"

- develop appropriate dissemination,

- invest in infrastructure and

- build elements of sustainability and continuity.

This framework (Figure 1) included four structural levels such as individual, team, organisation and supra-organisation, which each of these principles can be applied. This was later used in a team-based approach to evaluate the RCB activities using qualitative methods as

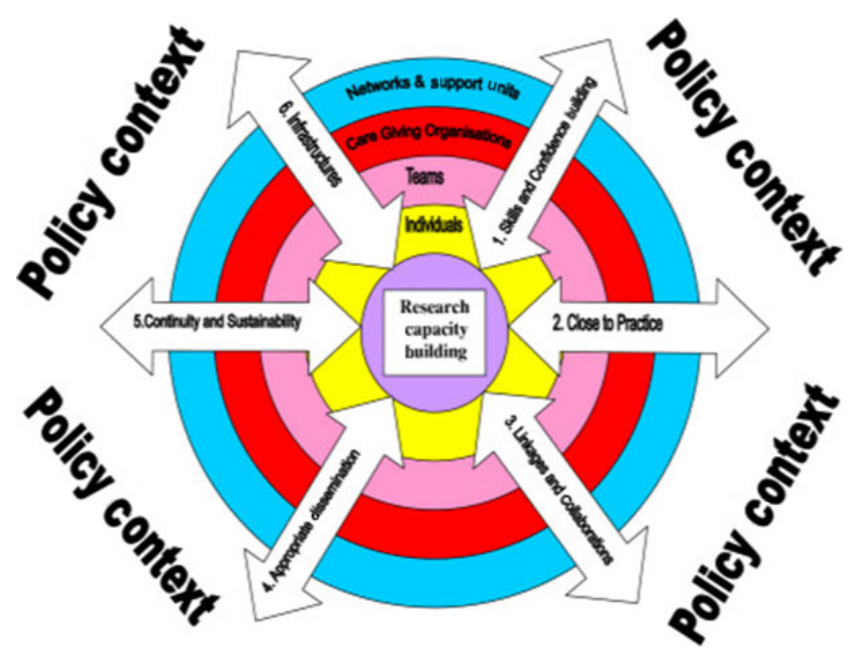

FIGURE 1 Research capacity building: a framework for evaluation (Cooke, 2005)

there was no quantitative scale had been existed based on this framework (Cooke, Nancarrow, Dyas, \& Williams, 2008).

Since then, Sarre and Cooke (2009) have developed indicators for these six principles. However, there was still no validated tool to measure research capacity or culture at all four levels, that is individual, team organisation and supra-organisation. In 2012, the Australian research capacity and culture (RCC) tool (Holden, Pager, Golenko, \& Ware, 2012) was developed to quantitatively measure research culture based on Cooke's framework.

Research capacity and culture contained a number of statements relevant to three levels (individual, team and organisation), and items are scored separately for each level or domain. Although the supraorganisation level was not included in the tool, there were items in the tool relating to the supra-organisational domain. The respondents rate these items on a scale of 1 to 10 , with 1 considered as the lowest skill or success level and 10 was the highest possible skill or success level.

In conclusion, according to the literature, RCC was the only validated tool available to measure the whole system approach to RCB activities. Hence, the RCC tool was selected as the best one to use to achieve the aims of this study. This Australian tool has not been used in any other healthcare systems, including in the UK. This thesis is the first one in the UK and outside Australia that used the tool and would therefore build upon the knowledge and evidence from the Australian RCC tool.

Organisation was considered to play an important role in developing research culture. When Snelgrove and James (2011) looked at the perception of graduate nurses on research and development culture in one of the Healthcare Trusts in the UK, it was found that participants who wished to conduct research were still hindered by organisational barriers and culture. Their study had two phases, phase 1 involving a questionnaire survey using a research culture index and phase 2 with focus groups looking at nurses' experience and barriers to research. Compared to this study, their study only used graduate nurses, and general nurses and AHPs were excluded 


\section{Clinical Nursing}

from the study. Lack of organisational research culture and education was seen as a main barrier in this study. It was interesting to note from their study that although graduate nurses had theoretical knowledge of research, this was not sufficient for them to actually carry out or conduct research. Also, as the nurses were not using their research skills and knowledge, it resulted in deskilling themselves and losing their confidence in research.

The research literature suggested that an organisation has an important role at different levels in developing an environment and culture that supports research. According to McNicholl, Coates, and Dunne (2008), a paradigm shift in organisational culture is important in order to promote research. llott and Bury (2002) also state that an organisational culture shift is required to overcome the challenges of increasing research use. It also required good collaborative effort, participation and input from all sectors within the organisation. Bland and Ruffin (1992) pointed out that research culture is affected by personal as well as organisational characteristics. They highlighted that when a scientist has been transferred to a less research-active organisation, then his or her research output also became reduced. Bland and Ruffin (1992:385) identified 12 characteristics affecting research productivity which were:

1. Clear goals that serve a coordinating function;

2. Research emphasis;

3. Distinctive Culture;

4. Positive group climate;

5. Assertive participative governance;

6. Decentralised organisation;

7. Frequent communication;

8. Accessible resources, particularly human being;

9. Sufficient size, age and diversity of the research group;

10. Appropriate rewards;

11. Concentration on recruitment and selection; and

12. Leadership with research expertise and skill in both initiating appropriate organisational structure and using participatory management practices.

There was some evidence in the literature to suggest that there needs to be a close link between three levels such as individual, team and organisation to promote research culture. In other words, a whole organisation approach is needed to achieve and promote research culture. This is supported by a recent Australian study by Golenko, Pager, and Holden (2012) in which semi-structured indepth interviews were carried out with nine AHP senior managers. The study concluded that research should be one of the important values of the organisation and managers should provide support through processes, structures and systems to advance research culture. Tanner and Hale (2002) also confirmed that support and facilitation of managers are very important to encourage a research culture.

Williams and Lazzarini (2015) suggested that the organisation was in a better position to influence nurses' and AHPs' research capacity and culture by creating links between and across the different levels, such as individual and team. A whole organisational approach can aid in maintaining and developing a research culture. Support and facilitation from managers were also highlighted as another aid to improve research culture (Begley, McCarron, HuntleyMoore, Condell, \& Higgins, 2014; Butterworth, 2010; Joffres et al., 2004). The roles of research champions or research leaders were considered influential for research culture. Barriers to research culture in nurses and AHPs were organisational issues, such as a lack of research management and support, and lack of knowledge and experience of research, alongside other barriers such as staffing, clinical priorities, finances and managerial support that were outside their control (Clifford \& Murray, 2001; Cooke et al., 2002; Daniels, 2002; Ried, Farmer, \& Weston, 2007). Clinical academic training programmes may aid in creating a prominent research culture throughout the NHS (Health Education England 2015) as a whole.

\section{AIM}

The primary aim of the research study was to explore the influence of research-focused exposure on the research culture of nurses and AHPs in the UK and to identify whether there was a difference in the research culture between a research-focused and non-researchfocused clinical area.

\section{1 | Context}

This study explored the research culture of nurses and AHPs based in two hospitals in the Northwest of England. One of the hospitals was research-focused (City Hospital) and the other was nonresearch-focused (Riverside Hospital). For clarity, and to protect anonymity, the actual names of both hospitals have been changed. The most research-active division of City Hospital is represented in this study as the "Seacole Division."

The City Hospital in this study was a large teaching hospital with university links, and the main area used for this study within the City Hospital was the Seacole Division. A division in a hospital was a group of specialities/department grouped under one operational management umbrella. Seacole division has always been a part of the City Hospital where the BRC and Nursing Midwifery and Allied Health Professional (NMAHP) strategy were implemented. However, Riverside Hospital did not have any research vision or research strategy. At the end of 2012, the Riverside Hospital joined the City Hospital. Prior to joining the City Hospital, Riverside Hospital had been a District General Hospital and a separate entity with its own organisational and management structure. Hence, it has not had any input from the research strategy or BRC. After joining the City Hospital, Riverside Hospital became a division. Therefore, it was an ideal opportunity to compare two areas to differentiate the research culture between a research-focused area and non-research-focused areas within a single organisation.

City Hospital was one of the major providers of tertiary and specialist healthcare services in UK, and it has treated more than a 


\section{Clinical Nursing}

million patients every single year. It had a strong vision and mission for research and, since 2008, has introduced many initiatives to increase research capacity and to improve research culture since 2008. Initiatives have included direct $\mathrm{DOH}$ funding and financial support from external agencies such as universities, city councils and regional developmental agencies. There has been significant input from the Department of Health and NIHR in awarding BRC status to the City Hospital from 2008. In this study, therefore, 2005-2008 is considered as a preresearch focus timeline and after 2008-2012 as postresearch focus timeline. Moreover, as explained in the earlier section, a number of other frameworks and strategies were implemented such as NMAHP research strategy to increase the research capacity and to change the research culture. However, the outcomes for this strategy on the research culture of its own staff were unknown; as this research culture was not explored or formally evaluated.

\section{DESIGN}

This was an empirical study using a mixed methodology, and therefore, quantitative and qualitative methods were used to substantiate and harmonise findings. However, there were no theories developed from this study. Quantitative methods used a cross-sectional Webbased survey to measure research culture using the research capacity and culture (RCC) tool (Holden et al., 2012), and the qualitative part was phenomenological design using focus group discussions and semi-structured interviews with senior managers.

\section{1 | Survey sample}

A convenience sampling type was used in this study because it was convenient to access the staff and facilities in both settings. The sampling used could also be considered as purposive sampling, as the aim was to focus on particular characteristics of the research culture of nursing and AHP staff and would enable staff to answer the research questions. As there was no formal hypothesis testing involved, a sample size calculation was deemed unnecessary for this study.

\section{2 | Focus groups}

The main reason for using focus groups in this study was to derive research data from groups of people, with more discussions and interaction. Also, it would have been harder, too, to undertake individual interviews of the nurses and AHPs as this would have clashed with patient care or had an adverse impact on patient care. The focus groups chosen in this study (the research-naive groups in City Hospital and Riverside Hospital and the research-active group from City Hospital) already existed.

Three focus group discussions were conducted. Two of them were interviewed by the research-naive staff in Ward A and Ward $\mathrm{B}$, and the third group was interviewed by the research-active group of the City Hospital. Table 1 illustrates the designation of the focus group participants in this study, and all the participants were females. The research-naive group was a pre-existing organisational structure in the wards where staff members from different disciplines joined together to discuss the care of their patients, especially follow-up care and discharge care. Research was never an agenda item for discussion. However, the research-active group of the City Hospital was set up with the purpose of supporting staff. The aim of the group was to support nurses and AHPs in the hospital with a research interest to develop their skills. The group had been in existence for 3 years at the time of the interviews (2013). As there was already a representative sample of research-active staff attending this group, it was convenient to select the focus group participants from this group. The aim of this group was to develop and promote a group or community of nursing, midwifery and AHP researchers throughout the hospital, provide peer support for any studies that the nurses and AHPs were doing and address any difficult issues they faced to develop and do research in their day-to-day clinical roles.

\subsection{Semi-structured interviews of the senior management team}

In the semi-structured interview, open-ended questions were asked of the participants based on a topic guide. There were five interviewees, including the Chief Nurse for City Hospital, Professor of Nursing, and the Heads of Nursing for both Seacole Division and City Hospital and the Head of AHPs, and these were all females. Although the interviewer was a senior manager in research at City Hospital, there was no direct relationship, line management or involvement in job responsibilities between the researcher and interview participants in this study. This was because the senior

TABLE 1 Focus group participants

\begin{tabular}{ll} 
Focus group & Participants \\
\hline $\begin{array}{l}\text { Research Active } \\
\text { Group (5 Participants) }\end{array}$ & Nursing research fellow working on a \\
& research project \\
& Community AHP consultant \\
& Research associate \\
& Renal advance nurse practitioner \\
& Rheumatology Research Coordinator \\
Research Naive & Ward manager/sister \\
Ward A (5 Participants) & Social worker \\
& Occupational therapist \\
& Physiotherapist \\
& Acute \& Rehab Dietetic Clinical Team Lead \\
& Occupational therapist \\
Research Naive & Clinical lead physiotherapist, intermediate \\
Ward B (4 Participants) & care team \\
& Ward manager, intermediate neuron \\
& rehabilitation \\
\hline & \\
&
\end{tabular}




\section{Clinical Nursing}

managers in this study were from the clinical management structure, whereas the interviewer belonged to the research management structure.

\section{5 | DATA COLLECTION}

\section{1 | Phase 1: Survey}

The survey was designed in the online survey tool Survey Monkey ${ }^{\mathrm{TM}}$ using the RCC tool (Holden et al., 2012) to measure research culture. All the nursing and AHP staff in the Seacole Division of City Hospital and all staff in the Riverside Hospital were invited to participate in the online survey. A generic email containing the survey information and link was sent to the workforce planning team of the hospital who then sent the survey email to all the nurses and AHPs in both divisions. The data collection was anonymous, with no means of identifying the participants who completed the survey. The number of questionnaires sent to City Hospital and Riverside Hospital was 541 and 400, respectively. The total number of responses received for this survey was 224 , and there were two incomplete questionnaires in the responses; however, the missing answers differed in each of these two questionnaires. Therefore, the incomplete questionnaires were also included in the analysis for each level. Missing answers were left as they were, for analysis purposes.

\subsection{Phase 2: Focus groups and Semi-structured interview}

In phase 2, after the survey data collection, three focus group discussions were conducted. Two of them were interviewed by the research-naive group in Ward A and Ward B, and the third group was interviewed by the research-active group of City Hospital.

In Ward A and Ward B, there were established meetings for the research-naive groups to discuss the patient care pathways. The focus group discussion in Ward B was carried out as a comparator because Riverside Hospital had no influence from the BRC or strategy. The discussions for the focus group involved questions around current research culture, their views on research culture and the issues they identified on research culture, using the preplanned questions using the interview guide. The questions in the guide were developed in conjunction with based on the findings from the survey.

This involved interviewing senior managers of City Hospital about their views on the research culture. The interview started with simple and open questions. The core part of the interview focused on the questions from the interview guide. This included many open-ended questions and also some closed questions. The interviewer had a checklist to follow during the interview, which comprised of what needed to be done as part of the interview. It may be argued that the checklist could break the communication flow. However, this was used in the interview as a guide without the need to refer to the checklist explicitly. The interviewer gave some prompts in between and asked circumstantial questions depending on how the discussions progressed. The interview felt like a natural exploratory conversation. Both semi-structured interviews and focus group discussions were recorded onto the digital recorder.

Both focus groups and interviews were conducted with different group of participants, that is, research-active groups, research-naive groups and senior managers. For example, to understand the research culture, focus groups were used with research-active and research-naive groups, and semi-structured interviews were conducted for senior managers individually.

\section{6 | ETHICAL ISSUES FOR THE STUDY}

The research project gained university and hospital approval to carry out this study. NHS ethics approval was not required as it did not involve any patient data. However, approval and governance checks were undertaken locally by hospitals and the university. For survey participants, there was no separate consenting process as their willingness to complete the survey was taken as their consent. A participant information sheet was provided for the focus group and interviewees, and informed, written consent was also obtained.

\section{7 | DATA ANALYSIS}

As this study has two methods, including qualitative and quantitative, methodological triangulation has been used in this study. Along with the survey results, both focus groups and individual interviews are combined in the qualitative data analysis of this study to explore the research culture more comprehensively.

\section{1 | Survey result analysis}

Phase 1 data analysis was completed using descriptive statistical methods, which helped to present the quantitative results in a meaningful way. The distribution of the categorical data in the RCC tool such as each item of research activity mentioned for individual, team and organisation level was analysed and presented in this study using percentage, median, standard deviation and interquartile range. The RCC tool had a 10-point scale in which 10 was the highest skill and 0 indicated no skill. These 0-10 scores were analysed as ordinal data to match with the categorical data used in the RCC tool ( $\mathrm{Hol}-$ den et al., 2012).To find out the difference between City Hospital and Riverside Hospital, Fisher's exact test or Chi-squared test was carried out for dichotomous variables in the RCC. These included survey participants' demographics, barriers, motivators and research activities. The P-value of $<0.05$ was used throughout the study to indicate the statistically significant difference between each hospital. Survey responses with missing answers were included in the analysis. However, there were no values assigned to the missing answers. The questions with no answers did not contribute to the analysis of that question. Also, to deal with missing answers and the relatively high rates of unsure responses, mean scores were calculated for 


\section{Clinical Nursing}

each person. Survey responses were automatically saved and recorded in the Survey Monkey ${ }^{\mathrm{TM}}$. A statistical package called $\mathrm{R} X$ 64.3.0.0 ${ }^{\mathrm{TM}}$ was used in this study for survey data analysis ( $R$ Core Team 2014).

\section{2 | Data analysis of semi-structured interviews and focus groups}

The data analysis was combined for both focus group and interview data to develop common themes, and framework analysis (Ritchie \& Spencer, 1994) was used to manage and sort the data systematically to generate themes. There were seven sections for the framework analysis process, and each one is explained below.

1. Transcribing the interview data;

2. Familiarisation with the interview;

3. Coding of the data;

4. Developing analytical framework;

5. Indexing or applying the analytical framework;

6. Charting data into the framework matrix; and

7. Interpreting the data (Ritchie \& Spencer, 1994).

Using NVivo, the interview transcripts were coded; however, after the first two transcripts were coded, around 92 codes were generated, which was not seen as an effective way of carrying out the coding process. Moreover, around 25 of the codes were only used once. Hence, it was decided to use Microsoft ${ }^{\mathrm{TM}}$ Word processor (manually) to generate the data and further data analysis.

\section{8 | VALIDITY AND RELIABILITY}

As this study has used mixed methods to cover a broad spectrum of issues related to research culture, this increased the generalisability. For data collection, verbatim transcription was used to increase the reliability, validity and the veracity of qualitative data collection (MacLean, Meyer, \& Estable, 2004 and Seale \& Silverman, 1997). Another action to improve the validity of the qualitative data was rechecking the audio recordings. The transcribed data were rechecked by replaying the audio recordings of the interviews and reading the transcription again. The same process was repeated by another qualitative researcher, which added to the validity of the data. For veracity, the researcher always maintained trust and was transparent about the research study (Gillon, 1994). To follow Kent's (2000: 64) rule of veracity, the researcher maintained: "an obligation to provide accurate information about the nature of the study when enlisting potential participants."

To enhance the reliability of the study, a number of measures were undertaken. For example, the RCC tool used in the survey was a valid and reliable questionnaire, developed in Australia (Holden et al., 2012). When the tool was modified for use in this current study, only a few words were changed in the titles of each section, without making any changes to the contents, such as changing "consumer" to "patient" and "organisation domains" to "hospital domains." Therefore, the validity of the tool was not affected. However, it was piloted and reviewed for any issues before the full survey was carried out by the researcher because of different context and geographical area (Australia and the UK). The pilot survey was carried out using a small group of 10 healthcare professionals including a few staff members, colleagues and supervisory team for the purpose of layout, format, grammar and content. The pilot helped to identify any problems or flaws and potential causes of confusion, such as any misleading questions which may have potentially resulted in invalidating the responses. Suggestions were also made to adapt the questionnaire to a more local context, and these were then incorporated into the survey questionnaire. Recording the interviews helped to obtain more reliable evidence and avoided any bias which might have happened if the researcher tried to recall or simply remember the conversation. This approach is supported in the literature by Gray (2013:624) who wrote: "in terms of reliability, it is fairly obvious that taped conversations will tend to present more reliable evidence than hastily written field notes." Reliability was further increased using triangulation in this study. As Arksey and Knight (1999) suggested triangulation is a strategy that can be used to strengthen the confidence in the results of the research finding. Gray (2004) also confirmed that use of different methods to collect the data in data triangulation would help in overcoming bias and any weaknesses that any individual method would have caused. As this study had collected data by different methods, the study was more reliable by reducing more personal and methodological biases.

Therefore, triangulation was used in this study to obtain different views about the same phenomenon and would result in increasing the validity and credibility of the study findings (Hussein, 2009).

\section{9 | RESULTS}

\section{1 | Survey results}

The total number of responses received for this survey was 224 giving a response rate of $24 \%$ (Riverside Hospital $22 \%$ and City Hospital $26 \%$ ). There were a higher number of female participants in the Seacole Division, $87.5 \%$ compared to $85 \%$ in Riverside Hospital from the total respondents for each division (Table 2). Male respondents were $12.5 \%(n=18)$ and $15 \%(n=12)$, respectively, for each hospital. The difference in this can probably be explained by the difference in the total numbers of male and female healthcare professionals nationally, as there always is a preponderance of female healthcare professionals in hospitals. As per the Health and Social Care Information Centre (2014) data on gender demographics, there were $81 \%$ of female healthcare professionals compared to $19 \%$ male professionals. Also, more nurses responded to the survey compared to AHPs in both areas (71.8\% nurses and $28.2 \%$ AHPs). The national census data (2014) showed that there are more nurses $(356,850)$ compared to AHPs $(156,723)$. More postgraduates responded to the survey compared to other qualified groups from both areas $35.4 \%(n=51)$ in Seacole division and $43 \%(n=34)$ in 


\section{Clinical Nursing}

TABLE 2 Survey results

\begin{tabular}{|c|c|c|c|}
\hline & City hospital & Riverside hospital & $p$-Value* \\
\hline Gender $(n=224)$ & 144 & 80 & .68 \\
\hline Female & $126(87.5 \%)$ & $68(85 \%)$ & \\
\hline Male & 18 (12.5\%) & $12(15 \%)$ & \\
\hline Occupation $(n=220)$ & 142 & 78 & .99 \\
\hline Allied & 40 (28.2\%) & $22(28.2 \%)$ & \\
\hline Nurse & $102(71.8 \%)$ & $56(71.8 \%)$ & \\
\hline Highest professional qualification $(n=223)$ & 144 & 79 & .03 \\
\hline $\mathrm{PhD}$ & $2(1.4 \%)$ & $2(2.5 \%)$ & \\
\hline Master's & 27 (18.8\%) & $7(8.9 \%)$ & \\
\hline Master's research & $10(6.9 \%)$ & $0(0 \%)$ & \\
\hline Certificate & $14(9.7 \%)$ & $12(15.2 \%)$ & \\
\hline Postgraduate & $51(35.4 \%)$ & $34(43 \%)$ & \\
\hline Undergraduate & $40(27.8 \%)$ & $24(30.4 \%)$ & \\
\hline Are you currently enrolled? $(n=222)$ & 143 & 79 & .16 \\
\hline $\mathrm{PhD}$ & $4(2.8 \%)$ & $0(0 \%)$ & \\
\hline Master's & $14(9.8 \%)$ & $5(6.3 \%)$ & \\
\hline Master's research & $4(2.8 \%)$ & $0(0 \%)$ & \\
\hline No & $121(84.6 \%)$ & 74 (93.7\%) & \\
\hline Did you know about BRC? $(n=223)$ & 143 & 80 & $<.001$ \\
\hline Yes & $103(72 \%)$ & 31 (38.8\%) & \\
\hline No & 27 (18.9\%) & $29(36.2 \%)$ & \\
\hline Unsure & $13(9.1 \%)$ & $20(25 \%)$ & \\
\hline Do we have a research strategy Q15 $(n=222)$ & 142 & 80 & .001 \\
\hline Yes & $71(50 \%)$ & $20(25 \%)$ & \\
\hline No & $12(8.5 \%)$ & $11(13.8 \%)$ & \\
\hline Don't know & 59 (41.5\%) & 49 (61.2\%) & \\
\hline Research is part of role description $(n=216)$ & 137 & 78 & .003 \\
\hline No & 70 (50.7\%) & 57 (73.0\%) & \\
\hline Yes & 67 (48.5\%) & 21 (26.9\%) & \\
\hline
\end{tabular}

${ }^{*}$ All from Fisher's exact test.

Riverside Hospital. Furthermore, there was a statistically significant difference in the aggregated score of qualification of City Hospital participants compared to Riverside Hospital $(p=.03$ ). This indicated that the respondents from City Hospital had higher qualifications compared to Riverside Hospital.

The survey results indicated that there was a difference in the research culture between City Hospital and Riverside Hospital. There was a statistically significant difference in knowledge about the BRC between City Hospital and Riverside Hospital $(p<.001)$. For the individual, team and organisational level capacity, there were statistically significant differences between City Hospital and Riverside Hospital $(p<.05)$. However, the mean scores for City Hospital at individual level (M1.98) were not high enough to support a strong research culture. Furthermore, the team level scores (M5.28) at City Hospital were also not high enough to indicate a very strong research culture at that level. Looking at the difference between nursing and AHP, the mean score for AHPs (M5.16) was higher on research culture compared to nurses ( $M$ 4.69) (Table 3). However, these differences were not statistically significant. Also, overall there were more reported barriers, motivators and research activities at City Hospital compared to Riverside Hospital (Tables 4 and 5). The survey item at individual level on "writing for publication in peer reviewed journals," had a mean score of M3.81 at City Hospital compared to M3.27 $(p<.0957)$ at Riverside Hospital. However, at team level, item on "the support for peer-reviewed publication of research" had a score of m 5.53 at City Hospital and M3.77 at Riverside Hospital with a $p$-value of $<.001$. At organisational level, City Hospital had M6.55 compared to M4.2 in Riverside Hospital $(p<.001)$.

\subsection{Correlations between Individual, team and organisational research capacity domains}

This was done to examine whether any level of research capacity mediated the link between the other levels. The $p$ values of correlation between each level were $<.001$ indicating that the correlation 


\begin{tabular}{|c|c|c|c|c|c|c|}
\hline & $\begin{array}{l}\text { City Hospital } \\
\text { M (SD) }\end{array}$ & $\begin{array}{l}\text { Riverside } \\
\text { Hospital } \\
\text { M (SD) }\end{array}$ & $p$-value* & $\begin{array}{l}\text { Nurse } \\
M(S D)\end{array}$ & $\begin{array}{l}\text { Allied } \\
\text { M(SD) }\end{array}$ & $p$-Value \\
\hline Mean Individual Score & $4.6(1.9)$ & $3.87(2.2$ & .003 & $4.24(2.0)$ & $4.54(2.1)$ & .38 \\
\hline Mean Team Score & $5.28(2.5)$ & $3.61(2.4)$ & $<.001$ & $4.51(2.6)$ & $5.10(2.6)$ & .14 \\
\hline Mean Organisational Score & $6.46(2.6)$ & $4.92(3.1)$ & $<.001$ & $5.94(2.9)$ & $5.92(2.9)$ & .94 \\
\hline Total & $5.35(2.1)$ & $3.90(2.2)$ & $<.001$ & $4.69(2.2)$ & $5.16(2.2)$ & .12 \\
\hline
\end{tabular}

${ }^{*}$ Results from Mann-Whitney $U$ test.

\begin{tabular}{llllllll} 
& Min & $\begin{array}{l}\text { 1st } \\
\text { Quartile }\end{array}$ & Median & Mean & $\begin{array}{l}\text { 3rd } \\
\text { Quartile }\end{array}$ & Max & $p$-Value* \\
City & 0.000 & 3.000 & 4.000 & 4.944 & 7.000 & 16.000 & .2 \\
Riverside & 0.000 & 3.000 & 5.000 & 5.375 & 7.000 & 17.000 & \\
\hline Nurse & 0.000 & 3.000 & 4.000 & 5.006 & 7.000 & 16.000 & .07 \\
AHP & 1.000 & 4.000 & 5.000 & 5.613 & 7.000 & 17.000 &
\end{tabular}

${ }^{*}$ Results from Mann-Whitney $\mathrm{U}$ test.

\begin{tabular}{lllllllll} 
& Min & $\begin{array}{l}\text { 1st } \\
\text { Quartile }\end{array}$ & Median & Mean & 3rd Quartile & Max & $p$-Value* \\
Total & 0.000 & 3.000 & 5.000 & 5.491 & 7.000 & 17.000 & \\
City & 0.000 & 3.000 & 5.000 & 5.66 & 8.000 & 16.000 & .29 \\
\hline Riverside & 0.000 & 3.000 & 4.000 & 5.188 & 6.250 & 17.000 & \\
Nurse & 0.000 & 3.000 & 5.000 & 5.399 & 7.750 & 16.000 & .41 \\
\hline AHP & 1.000 & 4.000 & 4.500 & 5.887 & 7.000 & 17.000 & \\
\hline
\end{tabular}

*Results from Mann-Whitney $U$ test.

was statistically significant between each levels. The same analysis was repeated for each hospital which shows that there was a correlation between each levels in both hospitals too $(p<.0001)$.

\section{3 | Qualitative data results}

Following the framework analysis of the qualitative data, the themes were developed. These were then categorised as specific and generic. Specific themes were different to each of the three levels (individual, team and organisational), and generic themes were generic to all three levels.

Specific themes are as follows:

- Lack of skills and knowledge at individual level;

- Support at team level; and

- Structures and facilities at organisational level.

The generic themes are as follows:

- Barriers and enablers of research culture;

- Communication;

- Career pathways;
TABLE 3 Mean individual score, mean team score and mean organisation score
TABLE 4 summary of the number of barriers/person for hospitals and profession
TABLE 5 Summary of number of motivations per person for area and profession
- External links and collaboration; and

- Motivators

The interview participants, including the managers from both areas, highlighted the lack of skills and knowledge about research at individual level for both areas. They believed that even with a research focus, it was hard to say that the staff at individual level were empowered to conduct or discuss about research or what they knew about research. They also pointed out that, because of this lack of awareness, nurses and AHPs at the ward level may not ask patients to participate in research. One participant made the following comment:

We don't use the latest evidences in our practice because we are not aware of any recent studies or evidence.

(C3:10-staff nurse)

They also suggested there is lack of support at middle-level management, which could be addressed by establishing structures, processes and systems to facilitate research available at the middle level. Senior managers from City Hospital also supported this by saying: 


\section{Clinical Nursing}

I think it depends upon the senior leadership within nursing and actually whether they see that as beneficial and a priority because I think actually without that drive at a senior level, so I'm, kind of, thinking head of nursing, lead nurse, matron level, unless it's actually on that agenda for that staff group, then it won't get taken forward at all.

(R3:6 Nurse Managers)

Riverside Hospital participants believed that having more research infrastructure would aid in research culture:

Having a BRC has helped to improve the research support and staffing available within the organisation. Certainly, the numbers of research staff and research studies have gone up. I have also noticed more funding calls to do more research projects, both internally and externally.

(A 2:4 -AHP)

There were a number of internal and external factors perceived as barriers and enablers in facilitating the research culture of the organisation at different levels. It was acknowledged that the motivators could be considered as enablers. These were mainly relationships with other organisations, workload pressure, staff shortages, lack of involvement from managers and peer and manager pressure. Almost all the participants and managers listed the majority of these barriers. As with barriers, managers and focus group participants identified enablers as a theme, as reflected in the comment below:

I think we need to give people time. We need to build capability of people. You want people to be researchers to improve practice, which then impacts on patient care and the quality and experience, but also we need people delivering direct care at the bedside. So we probably don't put enough resource in.

Both groups and even managers also suggested that communication is an important issue and that measures should be taken to improve communication between top (organisational) and bottom (individual) levels. These can be done by having a research link worker in each clinical area for research and having research as a standing agenda in team and staff meetings. It would bring up discussions about research amongst staff and staff opportunities to talk about and understand ongoing research:

We should actually have presence of research in our professional bodies, professional meetings, heads of nursing meetings, ward managers' meetings etc., it should be a standard agenda item which would bring up discussions about research and current evidences.

\section{(R1:15-Ward manager)}

There were also concerns raised by the focus group participants and managers in City Hospital about the lack of proper career pathways in research and hence lack of use of the skills acquired. It was also noted from the discussions that AHPs were more research active than nurses and that they tended to collaborate more with medical staff, depending on the nature of the project. Even the participants from Riverside Hospital arrived at the conclusion that AHPs were seen to be more research-active than nurses generally. Some indicated that the reason for this was the AHPs' personal motivation as gaining a master's degree was desirable for AHPs' career progression:

It's ideal to have a Masters if you are looking for a Career progression as an AHP.

(A3:23-Advanced nurse practitioner)

Participants believed that there needed to be stronger external partnerships, through strong communication, with other organisations, in particular universities:

It will be ideal to partner up with university to do more research and putting research proposals. But I don't know whether we do enough of that and whether we have enough external links or whether we don't hear about it.

(R3:19-Clinical Team Lead)

\section{0 | DISCUSSION}

Even though the survey response rate was low, this is similar to the response rate of $24 \%$ from a previous survey carried out in City Hospital. It is important to acknowledge that $24 \%$ is a better response rate than has been seen in these types of surveys where, for example, there was only a $6 \%$ response rate in Williams and Lazzarini's (2015) study using the RCC. To present the results of the study succinctly, the structural levels and RCB principles from Cooke's (2005) framework have been used.

The results of the qualitative part of this study identified the main themes which were divided into specific and generic levels. The specific themes were lack of skills and knowledge at individual level, support at team level and structures and facilities at organisational level. The generic themes identified from the analysis were barriers and enablers of research culture, communication, career pathways, external links and collaboration and motivators. The themes developed from the discussions were mainly based on both internal and external factors affecting research culture at different levels. The majority of these findings are in line with the current literature (Cooke, 2005; Holden et al., 2012) and provide empirical evidence to support the theories and concepts proposed by other researchers in the field. However, issues in communication at all levels and the wide gap in support at the middle level were highlighted more from this study compared to the previous literature. Furthermore, the participants suggested that there was more research culture evident in AHPs compared to nurses. So the new 


\section{Clinical Nursing}

knowledge derived from this study is that there is a wide gap in communication between different levels of individual, team and organisation. Also the study highlights that there is a gap in research culture at middle level and that this needs to be tackled to improve the research culture of healthcare organisation.

Both the survey results and the framework analysis of the interviews suggested that the research culture at individual level was not adequate in City Hospital. However, there was a statistically significant difference in the education of City Hospital staff compared with Riverside ( $p$.03), which may reflect the statistically significant cultural difference at individual level too ( $p$.003). This indicated that the individuals were lacking adequate skills to undertake the majority of aspects of research at their level. The mean score of individual skill for City Hospital was 4.6 compared to 3.87 for Riverside Hospital and had a $p$-value of .003 . The results which emerged from the framework analysis of the interviews were common, in so far as the focus group participants and managers from both areas identified a lack of research skills at individual level. However, both the survey results and interview results revealed that these skills were higher at City Hospital compared to Riverside Hospital. The study results indicated that these efforts were not adequate enough to develop "the skills and confidence" of staff at individual level, which was one of the six principles of Cooke's framework, as the mean score for the individual level research skills for City Hospital was $M<5(4.6)$. It was also interesting to note that City Hospital and Riverside Hospital had fairly consistent findings even though one had investment and the other did not. This might also raise other concerns around the cost-effectiveness and cost implications of this investment in research in City Hospital as, being a large investment with poor returns. Although this study has identified the barriers discussed in the literature, it also raised novel findings in barriers such as lack of communication at all levels and lack of support at middle level.

Following the Finch Report (Finch, Cornwell, Ward, \& McPhai, 2013), the NIHR has introduced career pathways for nurses and AHPs, post-Finch Report (2013), including an internship, master's programme (Research Methods) followed by doctoral, postdoctoral and senior clinical lectureship awards (NIHR 2015). However, there were not enough opportunities available even in City Hospital to accommodate nurses or AHPs who have undertaken such training and development. Furthermore, there were three interns selected in this year (2014) at City Hospital. As a result, this study has suggested some of the staff left the hospital due to lack of career progression. Therefore, the return on investment on the research focus and capacity building was too low. However, McMahon, Bishop, and Shaw (2000) acknowledged that in order to obtain the best return on investment in research capacity building, nurses who develop research skills should be given the opportunity to do so by providing a clear career pathway which integrates clinical and academic perspectives. This correlates with the principle of "sustainability of skills" as mentioned in Cooke's framework (Cooke, 2005). Maintaining highly skilled people in the organisation aids the promotion of better patient care and the motivation of staff. Organisational policies and structures should support the career progression of its staff.
This should provide opportunities to apply skills and also to empower the "sustainability of skills" (Cooke, 2005; DOH 2000; Sarre, 2002). Research awareness should also be cultivated during undergraduate training of nurses and AHPs.

Patients could benefit from the delivery of quality evidence-based care, staff would have a research-skilled person to motivate, advise and supervise them, and the organisation would be benefiting from a research-skilled member of staff to improve its own research performance and culture. Therefore, these individuals should be driving research in their own clinical areas as in Cooke's (2005) terms, "close to practice." However, this study indicated that this closeness to practice was not evident in City Hospital and that the investment had not turned into a reality, because of the staff on training programmes leaving City Hospital. The "Shape of Caring" report suggested that there should be greater development of postgraduate doctoral centres in Local Education and Training Boards (LETB) areas to promote clinical research and increase the number of clinical academics in practice.

Results from this study also indicated that the research culture at the individual level was also affected by communication issues. This was highlighted more by City Hospital than Riverside Hospital. One of the reason for this may be that gap in research information was available at the top level but not at the bottom level due to lack of communication. When looking at the results for the survey, the questionnaire provided no provision for assessing the communication issue and how important this was for both hospitals, even though the majority of City Hospital participants identified communication issues as a theme on research culture. The literature also pointed out that communication was one of the twelve identified organisational factors proposed by Bland and Ruffin (1992) affecting research productivity and culture. Bland and Ruffin (1992) identified communication as an important factor many years ago. So it is interesting that this study highlights the fact that communication is a key factor in creating a two-directional link between top and bottom levels, to improve research culture within an organisation.

City Hospital staff highlighted that there should be measures taken to improve communication between top (organisational) and bottom (individual) levels such as having a research link worker or research leader in each clinical area for research and having research as a standing agenda in team and staff meetings. They suggested that this would bring up discussions about research amongst staff and create opportunities to talk about and understand about research. The findings from this study complement the literature on the roles of research champions or leaders to foster a multidisciplinary "collegial research" (Blaber, Woltz, \& Bautistia, 2013; Segrott et al., 2006). This also tied in with Cooke's (2005) principle on developing the appropriate "infrastructures enhance Research Capacity Building." This infrastructure development of having a leader or link worker at the team level or middle level helps in breaking the communication barrier between organisational and individual levels.

Both the qualitative and quantitative results of the study indicated that the research culture at organisational level is higher compared to Riverside Hospital which could be expected considering the level of investment. The mean score for City Hospital was 6.46 


\section{Clinical Nursing}

compared to 4.92 for Riverside Hospital. City Hospital participants emphasised that there were more resources at the organisation level due to the BRC, networks and the research and innovation division. They also identified that there was a noticeable increase in research staff, studies and funding. This was supported by Riverside Hospital participants indicating that having much research infrastructure would aid in research culture. In the literature, Farmer and Weston's (2002) framework highlighted that it is important to have a focus at organisational level to reduce barriers, to provide mentorship and training and to improve collaborations and networking. This would help in research capacity building and promote a whole system approach to improve individual needs and research levels. However, there were some concerns raised by City Hospital participants on organisational support for disseminating the results locally, nationally and internationally. Participants also suggested that the organisational drive for publication was relatively low in both hospitals. However, one participant indicated that they were not even able to complete their publication because of a lack of support. Another item at organisational level which was to "have regular forums/bulletins to present research findings" had a mean score of M 6.29 at City Hospital compared to M4.22 at Riverside Hospital. However, this mean score was out of 10 and hence was slightly above the adequate level (5). At team level the mean score of "dissemination for research results at research forums/seminars" were M5.36 at City Hospital compared to M3.21 $(p<.001)$. These items had a statistically significant difference between both hospitals apart from at the individual level, in which there was no statistically significant difference for the item on dissemination ( $p<$.0957). When looking at how to present their results, City Hospital staff indicated that they were not sufficiently confident to publish or present the results; this could be explained by a lack of support at team level (as explained earlier). Even though the mean scores on the above items were above 5 for City Hospital, being a research-focused organisation, City Hospital still had room for improvement by providing support. Hence, City Hospital staff might have felt at the focus group discussions that they were not given enough support to present research findings. This area covers the principle of "Dissemination" from Cooke's framework (2005). Moreover, dissemination for research findings was highlighted by $\mathrm{DOH}$ through its policies.

The survey tool only measured three levels of research culture. However, there were survey items or questions in each level with a generic theme of "external links and collaboration." These items from the survey and the interview themes fit the supra-organisational level in Cooke's framework. The literature also suggested that a research culture involving partnerships and collaborations can provide access to more funding, resources and infrastructure (Golenko et al., 2012; Pickstone et al., 2008; HEFCE 2001, Perry, Grange, Heyman, \& Noble, 2008). Many participants from City Hospital pointed out that having a stronger link within the organisation at different levels and collaborating with external agencies and organisations would assist in raising the research culture.

\section{1 | Issues identified from this study}

The study also identified issues associated with maintaining a research culture in an organisation. These are lack of communication and collaboration at three levels, lack of support from the managers at team level, lack of knowledge, resources and funding available at individual level, lack of time and increased clinical pressure and lack of career pathways.

\section{RELEVANCE TO CLINICAL PRACTICE}

From the results of the study, more implementation plans could be put in place to improve the research culture of nurses and AHPs. Having a strong research culture would help to develop an environment in the organisation that would enable and support creative work to generate new knowledge and that would provide researchers with opportunities to interact, collaborate with other organisations and grow. From this study, it may not be appropriate to expect too many direct patient benefits. However, by understanding the ways in which to improve research culture, there may be an increase in the number of publications, presentations and changes in practice. Moreover, more people would come forward to research clinical issues. There would be a better appreciation of actual and potential gains for staff and patients, the healthcare organisation and its reputation, locally, nationally and internationally. By improving the research culture of nurses and AHPs, it might be postulated that patient care will be evidence-based and that this will improve the quality of care given directly to patients, thus increasing public confidence.

\section{2 | LIMITATIONS}

This is the first study that has used the RCC tool and interview methods to evaluate the research culture within City Hospital and in the UK, so a cautious approach should be applied when interpreting the results. The perceptions of senior managers, nurses and AHPs on research culture might be higher due to the promoting of change in the research at local level focus and also change in supporting the further development of nursing, midwifery and AHP strategies in City Hospital.

The poor survey response rate also may lead to biased findings due to nonresponse bias. As the survey collected data at a single point in time, it may be difficult to argue that the results from this study are generalisable without conducting more surveys at different time points. Because of the time and resource limitations in this study and the methodology adopted, only one survey was carried out. Therefore, it is suggested by this study that further evaluation is needed to assess the culture at different time frames to generalise the research findings. 


\section{3 | CONCLUSION}

The key findings from the study are discussed below.

\subsection{The key findings of the study}

- This is the first unique and novel study that combined and compared both nursing and AHP.

- This is the first study using RCC tool internationally.

- There was a difference in the research culture between the research-focused and non-research-focused area.

- The research culture of the research-focused organisation was slightly higher than adequate.

- There were statistically significant differences between researchfocused and non-research-focused areas in their research culture at individual, team and organisational levels.

- There are no significant differences in the research culture of nurses and AHPs.

- A whole-level approach needs to be carried out to promote research culture with a focus on team level.

- A whole organisation approach can assist in developing an environment and culture that supports research.

- In both research-focused and non-research-focused areas, the organisational drive for publication and dissemination was low.

- There are a number of barriers, enablers and motivators for research, and more were identified by the research-focused area.

- There were similarities between research-focused and nonresearch-focused areas on barriers, enablers and motivators of research.

- Issues in communication failings and a wide gap in middle-level support were highlighted more from this study compared to evidences in the literature.

- The six principles of Cooke's framework along with communication element need to be implemented to improve the research culture of an organisation.

The discussions clearly pointed out that a whole-level approach (i.e., organisation, team and individual) is essential in developing and maintaining the research culture of an organisation irrespective of its research focus. By improving communication and collaboration, at all levels, internal as well as with external agencies, networks, universities and organisations can help to improve the research culture. Along with other barriers and motivators, communication was considered as the most important factor in promoting research culture which was not highlighted enough by any of the literature examined. This study indicated that communication between all levels is an important factor for any framework for research capacity building or culture development, and suggested that Cooke's (2005) framework should include communication along with other factors. Also, the research strategies need to be communicated to staff at all levels. Managers should make sure that there are systems in place to provide support for staff to get involved in research. Moreover, there should be organisational core values and support from senior managerial staff at middle /team level to promote research culture. There should be proper career pathways for nurses and AHPs, and sustainability of staff should be considered for those who have completed their studies. Overall, research should not be restricted to those whose job description includes research. Nurses and AHPs working within a positive research culture promote patient participation in research, evidencebased practice and high-quality care. Therefore, healthcare organisations should strive to improve the research culture of nurses and AHPs by tackling the barriers that prevent it from flourishing.

\section{CONTRIBUTIONS}

Study design: $\mathrm{ML}, \mathrm{FD}, \mathrm{CH}$; data collection: $\mathrm{ML}, \mathrm{FD}, \mathrm{CH}$; analysis: $\mathrm{AR}$, $\mathrm{CH}$; and manuscript preparation: $\mathrm{ML}, \mathrm{CH}$.

\section{ORCID}

Manju Luckson iD http://orcid.org/0000-0001-5596-3881

\section{REFERENCES}

Albert, E., \& Mickan, S. (2003). Closing the gap and widening the scope. New directions for Research Capacity Building in primary health care. Australian Family Physician, 32(12), 1038-1040.

Arksey, H., \& Knight, P. T. (1999). Interviewing for social scientists: an introductory resource with examples. London, UK; Thousand Oaks, CA; New Delhi, India: SAGE Publications.

Begley, C., McCarron, M., Huntley-Moore, S., Condell, S., \& Higgins, A. (2014). Successful Research Capacity Building in academic nursing and midwifery in Ireland: An exemplar. Nurse Education Today. Elsevier Ltd, 34(5), 754-760.

Blaber, B., Woltz, P., \& Bautistia, M. (2013). Bedside research nurse champions: Enhancing research knowledge and multidisciplinary Research culture. In Neurocritical Care. Conference: 11th Annual Meeting of the Neurocritical Care Society Philadelphia, PA United States. Conference Publication: (var.pagings).

Bland, C. J., \& Ruffin, M. T. 4th (1992). Characteristics of a productive research environment: literature review. Academic Medicine, 67(6), 385-97.

Butterworth, T. (2010). Review: The challenges facing healthcare lecturers and professors to lead and promote a research-based culture for practice. Journal of Research in Nursing, 15(3), 259-260.

Cheetham, A. (2007). Growing a Research Culture. Address to the Academic Senate - University of Western Sydney, May, p. 5. [Accessed on 20th May 2014 -Online]http://www.uws.edu.au/__data/assets/ pdf_file/0018/7119/Item_3.6_Building_a_Research_Culture__Ta bled_Doc.pdf.

Clifford, C., \& Murray, S. (2001). Pre- and post-test evaluation of a project to facilitate research development in practice in a hospital setting. Journal of Advanced Nursing, 36(5), 685-695.

Conrad, P. (2008). To boldly go: a partnership enterprise to produce applied health and nursing services researchers in Canada. Healthcare Policy, 3(Special Issue), 13-30.

Cooke, J. (2005). A framework to evaluate Research Capacity Building in health care. BMC Family Practice, 6, 44.

Cooke, J., Nancarrow, S., Dyas, J., \& Williams, M. (2008). An evaluation of the "Designated Research Team" approach to building research capacity in primary care. BMC Family Practice, 9, 37. 


\section{Journal of \\ Clinical Nursing}

Cooke, J., Owen, J., \& Wilson, A. (2002). Research and development at the health and social care interface in primary care: a scoping exercise in one National Health Service region. Health \& Social Care in the Community. Blackwell Science Ltd, 10(6), 435-444.

Daniels, L. (2002). A bright future for dietitians - where is the evidence? Nutrition and Dietetics, 59(1), 29-37.

Department of Health (2000). Towards a strategy for nursing research and development. London: Department of Health.

Estabrooks, C. A. (1999). The conceptual structure of research utilization. Research in Nursing \& Health, 22(3), 203-216.

Farmer, E., \& Weston, K. (2002). A conceptual model for capacity building in Australian primary health care research. Australian Family Physician, 31(12), 1139-1142.

Finch, E., Cornwell, P., Ward, E. C., \& McPhail, S. M. (2013). Factors influencing research engagement: research interest, confidence and experience in an Australian speech-language pathology workforce. BMC Health Services Research, 13, 144.

Fitzpatrick, S. (2013). A survey of staffing levels of clinical academic UK medical I schools as at 31 July 2012, (July 2012). London: Medical Schools Council.

Francis, R. (2010). Independent inquiry into care provided by Mid Staffordshire NHS foundation trust: January 2005 - March 2009: Volume 1. London: The Stationery Office.

Francis, R. (2013). Report of the Mid Staffordshire NHS foundation trust public inquiry. London: The Stationery Office.

Frontera, W. R., Fuhrer, M. J., Jette, A. M., Chan, L., Cooper, R. A., Duncan, P. W., ... Tate, D. G. (2005). Rehabilitation medicine summit: building research capacity. Topics in Stroke Rehabilitation, 12, 68-80.

Gillon, R. (1994). Medical ethics: four principles plus attention to scope. BMJ (Clinical research ed.), 309(6948), 184-188.

Golenko, X., Pager, S., \& Holden, L. (2012). A thematic analysis of the role of the organisation in building allied health research capacity: a senior managers' perspective. BMC Health Services Research, 12(1), 276.

Gray, D. E. (2004). Doing Research in the Real World. London; Thousand Oaks; New Delhi: SAGE Publications.

Gray, D. E. (2013). Doing research in the real world. London, UK; Thousand Oaks, CA; New Delhi, India: SAGE Publications.

Happell, B. (2008). Barriers to implementing a nursing clinical development unit. Contemporary Nurse: A Journal for the Australian Nursing Profession, 29(1), 53-59.

Hassanein, R. S. (1988). Barriers to research in allied health. Journal of Allied Health, 17(3), 175-187.

Health Education England (2015). Clinical academic careers. [Online] [Accessed on 14th February 2015] http://hee.nhs.uk/work-progra mmes/clinical-academic-careers/.

Health and Social care Information (n.d.) NHS Workforce Statistics December (2014). Provisional statistics http://www.hscic.gov.uk/sea rchcatalogue?productid=17373\&topics=0/Workforce\&sort=Relevance \&size $=10$ \&page=1\#top (Accessed on 30th March 2015).

Higher Education Funding Council for England (HEFCE) (2001). Research in nursing and allied health professions. Report of the Task Group 3 to HEFCE and the Department of Health.

Holden, L., Pager, S., Golenko, X., \& Ware, R. S. (2012). Validation of the research capacity and culture (RCC) tool: Measuring RCC at individual, team and organisation levels. Australian Journal of Primary Health, 18(1), 62-67.

Hussein, A. (2009). The use of Triangulation in Social Sciences Research: Can qualitative and quantitative methods be combined? Journal of Comparative Social Work, 1, 1-12.

Ilott, I., \& Bury, T. (2002). Research capacity: A challenge for the therapy professions. Physiotherapy, 88(4), 194-200.

Jenerette, C. M., Funk, M., Ruff, C., Grey, M., Adderley-Kelly, B., \& McCorkle, R. (2008). Models of inter-institutional collaboration to build research capacity for reducing health disparities. Nursing Outlook, 56(1), 16-24.

Joffres, C., Heath, S., Farquharson, J., Barkhouse, K., Latter, C., \& MacLean, D. R. (2004). Facilitators and challenges to organizational capacity building in heart health promotion. Qualitative Health Research, 14(1), 39-60.

Kent, G. (2000). Ethical principles. In D. Burton (Ed.), Research training for social scientists: A handbook for postgraduate researchers, (Sage Research Methods) (pp. 61-68). London, UK: Sage.

Kitson, A., Harvey, G., \& McCormack, B. (1998). Enabling the implementation of evidence based practice: a conceptual framework. Quality in Health Care: QHC, 7(3), 149-158.

MacLean, L. M., Meyer, M., \& Estable, A. (2004). Improving accuracy of transcripts in qualitative research. Qualitative Health Research, 14(1), 113-123.

Mant, D. (1997). National working party on $R \& D$ in primary care final report. London: NHSE: South and West.

McCormack, B., McCarthy, G., Wright, J., Slater, P., \& Coffey, A. (2009). Development and testing of the Context Assessment Index (CAl). Worldviews on Evidence-Based Nursing, 6(1), 27-35.

McMahon, A., Bishop, V., \& Shaw, T. (2000). Nurse Executive Directors Making a Difference: Report of a Workshop. In Royal College of Nursing Annual Nursing Research Conference, p. Recommendation Number ix, page 11.

McNicholl, M. P., Coates, V., \& Dunne, K. (2008). Driving towards an improved research and development culture. Journal of Nursing Management, 16(3), 344-351.

Moore, A. P. (1997). Research, the collaborative approach: Clinicians and academics. Physiotherapy, 83(5), 229-234.

Moore, J., Crozier, K., \& Kite, K. (2012). An action research approach for developing research and innovation in nursing and midwifery practice: Building research capacity in one NHS foundation trust. Nurse Education Today, 32(1), 39-45.

NIHR (2015). ICA HEE/NIHR Integrated Clinical Academic Programme for non-medical healthcare professions. [Online] http://www.nihr.ac.uk/f unding/nihr-hee-cat-programme.htm Accessed on 27th March 2015.

Nursing and Midwifery Council (2013). NMC response to the Francis report. PET clinics. London; NMC pp. v-vii.

Orme, J., \& Powell, J. (2008). Building research capacity in social work: process and issues. British Journal of Social Work, 38(5), 988-1008.

Perry, L., Grange, A., Heyman, B., \& Noble, P. (2008). Stakeholders' perceptions of a research capacity development project for nurses, midwives and allied health professionals. Journal of Nursing Management, 16(3), 315-326.

Pickstone, C., Nancarrow, S., Cooke, J., Vernon, W., Mountain, G., Boyce, R. A., \& Campbell, J. (2008). Building research capacity in the allied health professions. Evidence and Policy, 4, 53-68.

R Core Team (2014). R: a language and environment for statistical computing. Vienna, Austria: R Foundation for Statistical Computing, https:// www.R-project.org.

Ried, K., Farmer, E. A., \& Weston, K. M. (2007). Bursaries, writing grants and fellowships: a strategy to develop research capacity in primary health care. BMC Family Practice, 8, 19.

Ritchie, J., \& Spencer, L. (1994). Qualitative data analysis for applied policy research. In A. Bryman, R. G. Burgess (Eds.), The qualitative researcher's companion (pp. 173-194). London: Routledge.

Rosser, W., Godwin, M., \& Seguin, R. (2010). Family medicine Research Capacity Building: five-weekend programs in Ontario. Canadian Family Physician Medecin de Famille Canadien, 56(3), e94 e100.

Sarre, G. (2002). Capacity and activity in research project (CARP): supporting $R \& D$ in primary care trusts. Nottingam: Trent Focus.

Sarre, G., \& Cooke, J. (2009). Developing indicators for measuring Research Capacity Development in primary care organizations: A consensus approach using a nominal group technique. Health and Social Care in the Community, 17(3), 244-253. 


\section{Journal of \\ Clinical Nursing}

Seale, C., \& Silverman, D. (1997). Ensuring rigour in qualitative research. The European Journal of Public Health, 7(4), 379-384.

Segrott, J., Mclvor, M., \& Green, B. (2006). Challenges and strategies in developing nursing research capacity: A review of the literature. International Journal of Nursing Studies, 43, 637-651.

Shera, W. (2008). Changing organizational culture to achieve excellence in research. Social Work Research, 32(4), 275-280.

Snelgrove, S., \& James, M. (2011). Graduate nurses' and midwives' perceptions of research. Journal of Research in Nursing, 16(1), 7-20.

Tanner, J., \& Hale, C. (2002). Research-active nurses' perceptions of the barriers to undertaking research in practice. Nursing Times Research, 7 (5), 363-375.

Trostle, J. (1992). Research Capacity Building and international health: Definitions, evaluations and strategies for success. Social Science and Medicine, 35, 1321-1324.

Waine, M., Magill-Evans, J., \& Pain, K. (1997). Alberta occupational therapists' perspectives on and participation in research. Canadian Journal of Occupational Therapy, 64(2), 82-88.

Wilkes, L., \& Jackson, D. (2013). Enabling Research cultures in nursing: Insights from a multidisciplinary group of experienced researchers. Nurse Researcher, 20(4), 28-34.
Williams, C. M., \& Lazzarini, P. (2015). The research capacity and culture of Australian podiatrists. Journal of Foot and Ankle Research, 8(1).

Willis, L. (2015). Raising the bar. Shape of caring: A review of the future education and training of registered nurses and care assistants. London: HEE.

Woodward, V., Webb, C., \& Prowse, M. (2007). The perceptions and experiences of nurses undertaking research in the clinical setting. Journal of Research in Nursing, 12(3), 227-244.

How to cite this article: Luckson M, Duncan F, Rajai A, Haigh C. Exploring the research culture of nurses and allied health professionals (AHPs) in a research-focused and a nonresearch-focused healthcare organisation in the UK. J Clin Nurs. 2018;27:e1462-e1476. https://doi.org/10.1111/ jocn.14264 